\title{
Health care for children with diabetes mellitus from low- income families in Ontario and California: a population-based cohort study
}

\author{
Sunitha V. Kaiser MD MSc, Vandana Sundaram MPH, Eyal Cohen MD MSc, Rayzel Shulman MD PhD, \\ Jun Guan MSc, Lee Sanders MD MPH, Astrid Guttmann MDCM MSc
}

Abstract

Background: Children with diabetes mellitus in low-income families have poor outcomes, but little is known as to how this relates to healthcare system structure. Our objective was to gain insight into how best to structure health systems to serve these children by describing their health care use in 2 health system models: a Canadian model, with an organized diabetes care network that includes generalists, and an American model, with targeted support services for children from low-income families.

Methods: We performed a population-based retrospective cohort study involving children aged 1-17 years with type 1 diabetes mellitus. We used administrative data from between 2009 and 2012 from the California Children's Services program and Ontario. We used Ontario Drug Benefit Program enrolment to identify children from low-income families. Proportions of children receiving 2 or more routine diabetes visits per year were compared using $\chi^{2}$ tests, and diabetes-complication hospital admission rates were compared using direct standardization.

Results: More California children from low-income families $(n=4922)$ received routine care for diabetes from pediatric endocrinologists $(63.9 \%$ v. $26.9 \%, p<0.001)$ and used insulin pumps $(22.8 \%$ v. $16.4 \%, p<0.001)$ than Ontario children $(n=2050)$.California children from low-income families were less likely than Ontario children to receive 2 visits for routine diabetes care per year $(64.7 \%$ v. $75.7 \%, p<0.001$ ), and had slightly higher per-patient year hospital admission rates for diabetes complications (absolute differences $0.02,95 \%$ confidence interval [Cl] 0.02-0.02, for boys; $0.03,95 \% \mathrm{Cl} 0.03-0.03$, for girls).

Interpretation: Ontario children from low-income families received more routine diabetes care than did California children from lowincome families. Both groups of children had clinically comparable rates of hospital admission for diabetes complications. Diabetes care networks that integrate generalists may play a role in improving access and outcomes for the growing population of children with diabetes.

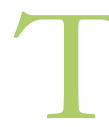
he prevalence of type 1 diabetes mellitus in children has been growing rapidly; between 2001 and 2009, it rose $22 \%$ in the United States (from 1.5 to 1.9 per 1000$)^{1}$ and $34 \%$ in Canada (from 2.0 to 3.0 per 1000) among children aged 19 years or younger. ${ }^{2}$ Children with diabetes mellitus have severe morbidity and 3 -fold increased mortality, ${ }^{3}$ primarily because of acute, potentially preventable complications ${ }^{4}$ (e.g., diabetic ketoacidosis). Children from low-income families are at the highest risk - they have poorer disease control, higher rates of life-threatening complications and worse outcomes. ${ }^{5-7}$ It is unknown how different health system models affect health care delivery and outcomes for children with diabetes mellitus.

In Ontario, residents have universal access to health care, and children with diabetes receive care from a network of specialized centres that integrate generalists. Because health insurance is universal, few programs specifically target support to children from low-income families. In contrast, in the US, care for children with diabetes mellitus is covered by a variety of health-insurance payers (e.g., public, commercial, managed-care), as well as a variety of care system structures (e.g., independent medical providers, health management organizations). Federal funds (from Title $\mathrm{V}$ of the Social Security Act) enable programs such as California Children's Services to target supports for children from low-income families who have chronic diseases, including diabetes. ${ }^{8}$

Competing interests: None declared.

This article has been peer reviewed.

Correspondence to: Astrid Guttmann, astrid.guttmann@ices.on.ca CMAJ Open 2016. DOI:10.9778/cmajo.20160075 
The primary aim of this study was to gain insight into how best to structure health care systems to meet the needs of children with diabetes mellitus from low-income families by describing their demographics and patterns of health care use in these 2 health system models. The secondary aim of this study was to examine outcomes across socioeconomic status within Ontario to better put our findings in context.

\section{Methods}

\section{Data source and study design}

We performed a retrospective cohort analysis using wellvalidated population-based administrative health databases from California Children's Services ${ }^{9}$ and Ontario. ${ }^{10,11}$ The California Children's Services database contains demographics and information on all paid hospital, emergency department and outpatient visits for enrollees. This database has not been formally validated, but it has been used in previous studies involving children with diabetes., ${ }^{9,12}$

Ontario databases were linked via unique encoded individual identifiers. These databases included the Ontario Diabetes Database, a validated population-based database of all Ontario residents with diabetes mellitus; ${ }^{13,14}$ the Registered Persons Database (demographics); the Ontario Health Insurance Plan (OHIP) Database (physician billing claims), from which diabetes diagnoses codes have been used in validation studies; ${ }^{13,14}$ the Ontario Drug Benefit Program Database; the Hospital Discharge Abstract Database, for which a diabetes diagnosis was found to be accurate in $94.5 \%$ of charts included in a large re-abstraction study; ${ }^{15}$ the National Ambulatory Care Registry (emergency department information), with $84 \%$ overall interrater reliability of diagnosis information; ${ }^{10}$ the Physician Database; and the Assistive Devices Program database, which although not formally validated, includes information on the prevalence of use of insulin pumps in children that matches prospectively collected data on this population. ${ }^{16}$ In addition, we used the 2006 Canadian Census to assign neighbourhood income quintiles to Ontario residents.

\section{Study population and setting}

We included all children aged 1-17 years with diabetes mellitus from 2009 to 2012 who were either enrolled in the California Children's Services program or residing in Ontario. We identified children in the California Children's Services program with diabetes mellitus by identifying children with the International Classification of Diseases, 9th revision, Clinical Modification (ICD-9-CM) code 250 (diabetes mellitus) listed as the eligible diagnosis code and with at least 1 insulin claim (Appendix 1, available at www.cmajopen.ca/content/4/4/E729/ suppl/DC1). ${ }^{12}$ In Ontario, we used the Ontario Diabetes Database $^{13}$ and divided children between 2 cohorts: those with Ontario Drug Benefit Program claims (children from lowincome families) and all other children. We restricted all cohorts to children enrolled in health care for 365 or more consecutive days. For the main 2 cohorts, California Children's Services and Ontario Drug Benefit Program, we restricted inclusion to children with type 1 diabetes mellitus by excluding all children using oral hypoglycemic agents (used primarily in type 2 diabetes mellitus) based on drug identification numbers (Ontario) and national drug codes (California) (Appendix 1).

California and Ontario are the most populous state and province in the US and Canada, respectively. ${ }^{17,18}$ In 2010, children younger than 18 years of age represented $25 \%$ of the California population, and children less then 20 years of age represented $23 \%$ of the Ontario population. ${ }^{19,20}$ California Children's Services supports care for children from lowincome families with certain chronic diseases, including diabetes mellitus. ${ }^{8}$ The program sets resource and care standards $s^{21,22}$ for the multidisciplinary care of children with diabetes mellitus at California Children's Services-approved clinics, and can provide supplemental funding for clinics to meet these standards. California Children's Services also provides supplemental coverage for medical devices (e.g., glucometers, lancets) and case-management support (public health insurance enrolment, accessing care through California Children's Services-approved centres, securing transportation, monitoring adherence).

In Ontario, residents have access to universal government insurance that covers all medically necessary health care services, with the exception of prescription drugs. Drug costs are handled out of pocket, with private extended health benefits, or through the Ontario Drug Benefit Program (covers people aged $>65 \mathrm{yr}$ and people who receive social assistance). Medical care for children with diabetes mellitus in Ontario is provided by the Ontario Paediatric Diabetes Network, which consists of specialized pediatric diabetes centres (30 secondary level and 5 tertiary level). These centres have multidisciplinary core teams that consist of nurses, dieticians and social workers who work closely with the physicians. Some centres are staffed by generalist physicians (pediatricians or family physicians) but would have access to consultation by pediatric endocrinologists from the tertiary centers. ${ }^{16,23}$

\section{Patient characteristics}

Socioeconomic status for children in Ontario was described using Ontario Drug Benefit Program enrolment and neighbourhood income quintile at the level of the dissemination area (representing a population of about 400-700 people) and adjusted for household and community size. ${ }^{24}$ Children were eligible for the Ontario Drug Benefit Program if their expected prescription costs were more than $4 \%$ of household income, or if their families were receiving social assistance. Children were eligible for California Children's Services if medical expenses were more than $20 \%$ of household income ${ }^{8}$ or if household income was less than $250 \%$ of the federal poverty line (annual household income < US\$22 050 in 2009). ${ }^{25}$ For children in California Children's Services, race and primary insurance were used to describe socioeconomic status. During the study period, children in California qualified for Medicaid if household income was less than $100 \%-133 \%$ of the federal poverty level. ${ }^{26}$

We identified insulin pump use using the Assistive Devices Program database (Ontario) and billing claims for insulin 
pumps or pump batteries (California) (Appendix 1). We determined specialty of diabetes care providers by identifying the physician who provided most of the outpatient diabetes care (diagnosis ICD-9-CM code 250.xx), then using the physician database (Ontario) and the National Provider Identifier (California). Distance from nearest diabetes centre was determined using home postal code..$^{27} \mathrm{We}$ defined urban location in California using the United States Department of Agriculture definition (county population $\geq 250000$ ), ${ }^{28}$ and in Ontario using the Statistics Canada definition ( $\geq 400$ people/ $\left.\mathrm{km}^{2}\right) .{ }^{18}$ Any missing data were described.

\section{Outcome measures}

We determined rates of hospital admission for diabetes mellitus complications using the specifications of the Agency for Healthcare Research and Quality (primary diagnoses of diabetic ketoacidosis, diabetes with hyperosmolarity, diabetes with coma or uncontrolled diabetes). ${ }^{29}$ We translated ICD-9 -CM codes to ICD-10 codes for Ontario (Appendix 1). We excluded admissions to hospital for therapy initiation, defined as an admission that started within 30 days of diagnosis (Ontario) or enrollment in California Children's Services (California). We determined the proportion of children receiving 2 or more routine outpatient visits for diabetes care per year (Appendix 1), ${ }^{30-32}$ rates of emergency department visits for complications of diabetes mellitus not resulting in an admission to hospital (using the same codes as admissions for diabetes mellitus complications) and rates of all other hospital admissions (to explore whether there may be different admission thresholds across jurisdictions).

\section{Statistical analyses}

We did separate but parallel analyses on both cohorts because privacy legislation does not allow data from the 2 jurisdictions to be merged. We compared characteristics of children in our low-income cohorts (California and Ontario) using $\chi^{2}$ tests for categorical variables and Student $t$ tests for continuous variables. To compare rates of hospital admission for diabetes mellitus complications per person-year, we used direct standardization to control for differences in age distribution and stratified by sex (standardized to 2010 California age distribution). ${ }^{17} \mathrm{We}$ then calculated absolute differences of rates with $95 \%$ confidence intervals (CIs). We compared proportions of children receiving 2 or more routine visits for diabetes mellitus per year using $\chi^{2}$ tests. We compared characteristics and health care use within Ontario, comparing children from low-income families to all other Ontario children. In addition, we performed a sensitivity analysis that included only children using insulin pumps (to explore whether rates differed by pump use). SAS version 9.2 (SAS Institute) was used for analyses.

\section{Ethics approval}

This study was approved by the Hospital for Sick Children (Toronto, Ont.), Sunnybrook Health Sciences Centre (Toronto) and Stanford University (Palo Alto, Calif.) research ethics boards.

\section{Results}

Characteristics of children with diabetes mellitus from lowincome families in California (California Children's Services) and Ontario (Ontario Drug Benefit Program) are described in Table 1 . There were 4922 children with diabetes from lowincome families in California (11 836 patient-years, mean = $2.4 \mathrm{yr}$ per child) and 2050 children with diabetes from lowincome families in Ontario (5300 patient-years, mean $=2.6 \mathrm{yr}$ per child). There was a smaller proportion of boys in the California cohort $(p<0.001)$. A higher proportion children in the California cohort were on insulin pumps compared with children in the Ontario cohort $(22.8 \%$ v. $16.4 \%, p<0.001)$. More than twice as many children from low-income families in California had diabetes mellitus care provided by pediatric endocrinologists compared with Ontario children $(63.9 \%$ v. $26.9 \%, p<0.001)$.

Age-standardized rates of hospital admission for diabetes mellitus complications are presented in Figure 1. Children from low-income families in Ontario had lower rates than their peers in California (0.06 v. 0.08 admissions/patient-year for boys and 0.08 v. 0.11 admissions/patient-year for girls, absolute differences 0.02 [95\% CI 0.02-0.02] for boys and 0.03 [95\% CI 0.03-0.03] for girls).

Table 2 shows a higher proportion of children from lowincome families in Ontario received 2 or more routine diabetes visits per year compared with children in California $(75.7 \%$ v. $64.7 \%, p<0.001)$. Children from low-income families in Ontario and California had equal rates of visits to emergency departments for diabetes complications ( 0.03 visits/patient-year, $p=1$ ). We found no differences in rates of other admissions to hospital.

\section{Ontario children from low-income families compared with all other Ontario children}

A lower proportion of Ontario children from low-income families (Ontario Drug Benefit Program) were using insulin pumps compared with all other Ontario children $(16.4 \% \mathrm{v}$. $23.5 \%, p<0.001$ ) (Table 3). Children from low-income families in Ontario had higher rates of hospital admission for diabetes complications compared with all other Ontario children with diabetes mellitus $(0.06$ v. 0.02 admissions/patient-year for boys and 0.08 v. 0.03 admissions/patient-year for girls; absolute differences $0.04,95 \%$ CI $0.04-0.04$, and 0.05 , 95\% CI $0.05-0.05$, respectively). However, a slightly higher proportion of children from low-income families received 2 or more routine diabetes visits per year $(75.7 \%$ v. $71.0 \%, p<$ 0.001) compared with all other Ontario children.

\section{Comparisons in uses of insulin pumps}

Among children from low-income families in California, age- and sex-standardized rates of hospital admission for diabetes mellitus complications were lower for children with insulin pumps than for those without $(0.07,95 \%$ CI $0.06-0.08$, v. 0.09 , 95\% CI 0.09-0.10, admissions/patient-year; absolute difference $0.02,95 \%$ CI $0.02-0.02])$. For children in Ontario, there were no differences by pump status. There were no differ- 


\section{OPEN}

\section{Research}

Table 1: Characteristics of children with diabetes mellitus from low-income families in Ontario and California

\begin{tabular}{|lcr|}
\hline Characteristic & $\begin{array}{c}\text { California } \\
n=4922\end{array}$ & $\begin{array}{c}\text { Ontario } \\
n=2050\end{array}$ \\
\hline Male sex, no. (\%) & $2265(46.0)$ & $1077(52.5)$ \\
\hline Age, yr & $10.8 \pm 3.9$ & $10.5 \pm 4.1$ \\
\hline Mean \pm SD & $11(8-14)$ & $11(8-14)$ \\
\hline Median (IQR) & & $273(13.3)$ \\
\hline Income quintile, no. (\%)† & & $339(16.5)$ \\
\hline 5 (highest) & & $360(17.6)$ \\
\hline 4 & & $431(21.0)$ \\
\hline 3 & $637(31.1)$ \\
\hline 2 & & $10(0.5)$ \\
\hline 1 (lowest) & &
\end{tabular}

Type of insurance, no. (\%)‡

Medicaid

$2511(51.1)$

Healthy families

$350(7.1)$

CCS-only

$88(1.8)$

Mixed§

$1973(40.1)$

Race, no. (\%)‡

White

1396 (28.4)

Black $444(9.0)$

Hispanic

$2288(46.5)$

Native American

$20(0.4)$

Asian/Pacific Islander

190 (3.9)

Other

471 (9.5)

Unknown

113 (2.3)

Insulin pump, no. (\%)

$1124(22.8)$

$336(16.4)$

$<0.001$

DM care provider type, no. (\%)

Pediatric endocrinologist

Pediatrician

Adult endocrinologist

3144 (63.9)

$551(26.9)$

676 (13.7)

$971(47.4)$

Reference

Family physician

$32(0.7)$

$81(4.0)$

$<0.001$

Internal medicine

74 (1.5)

$172(8.4)$

$<0.001$

$8(0.2)$

Unknown

$627(12.7)$

Other

341 (6.9)

$24(1.2)$

$<0.001$

Distance to nearest DM centre, $\mathrm{km}$

$\begin{array}{lccr}\text { Mean } \pm \text { SD } & 46.2 \pm 53.6 & 16.5 \pm 23.8 & <0.001 \\ \text { Median (IQR) } & 25.6(12.2-59.9) & 8(4-20) & <0.001 \\ \text { Location, no. (\%) } & & & \\ \text { Rural } & 155(3.2) & 273(13.3) & 1775(86.6) \\ \text { Urban } & 4767(96.9) & & \end{array}$

Note: $\mathrm{CCS}=$ California Child Services, $\mathrm{DM}=$ diabetes mellitus, IQR = interquartile range, $\mathrm{SD}=$ standard deviation

${ }^{*}$ Determined using $\chi^{2}$ test for categorical variables and Student's $t$ test for continuous variables.

†Only calculated for Ontario children.

$\ddagger$ Only calculated for California children.

$\S$ Children who switched insurance status during the time period. 
ences in rates of hospital admission for diabetes complications between children from low-income families with insulin pumps from California or Ontario.

\section{Interpretation}

In this large, population-based, cross-national study, we found significant differences in health care delivery for children with type 1 diabetes mellitus from low-income families. Care for most children from low-income families in California was provided by pediatric endocrinologists, whereas in Ontario, care was provided by general pediatricians. Ontario children from low-income families were more likely to receive routine care for diabetes mellitus compared with California children from low-income families, but had clinically comparable rates of admission to hospital for diabetes mellitus complications.

Major structural differences exist in how care is provided in California and Ontario, and these differences may contribute to some of our findings. In Ontario, the Ontario Paediatric Diabetes Network aids generalists in providing diabetes care by linking them to pediatric endocrinologists and multidisciplinary teams at tertiary centres. ${ }^{8}$ In contrast, most physician care in California Children's Services is provided directly by pediatric endocrinologists. Given the higher rates of routine visits and clinically comparable rates of diabetes mellitus complication in Ontario, our findings suggest that models of care with generalists practising within multidisciplinary diabetes settings may be effective. Previous studies comparing care models of subspecialist versus shared-care (generalists and pediatric endocrinologists) for children with diabetes mellitus found no differences in adherence to guideline recommendations or glycemic control. ${ }^{5,30}$ Shared care models may help overcome geographic barriers to accessing care, which is important in the context of our findings that children in California Children's Services lived further from the nearest diabetes mellitus centres. ${ }^{30}$ Given the rising prevalence of diabetes mellitus, shared-care models may become essential for meeting health care needs of this growing population. A 2008 US study found substantial geographic dis- parities in supply of pediatric endocrinologists. ${ }^{33}$ The authors concluded that shared-care models and increased capacity of primary care physicians were essential to address the needs of children with diabetes mellitus. ${ }^{33}$

We found lower complication rates for children from lowincome families in California who used insulin pumps compared with those who did not. Previous Canadian work investigating the relationship between social determinants of health and glycemic control in children with diabetes mellitus showed that children with the most deprivation had poorer glycemic control and lower rates of pump use; however, pump use had a moderating effect on socioeconomic gradients in glycemic control. ${ }^{7}$ This is in line with our findings for children from

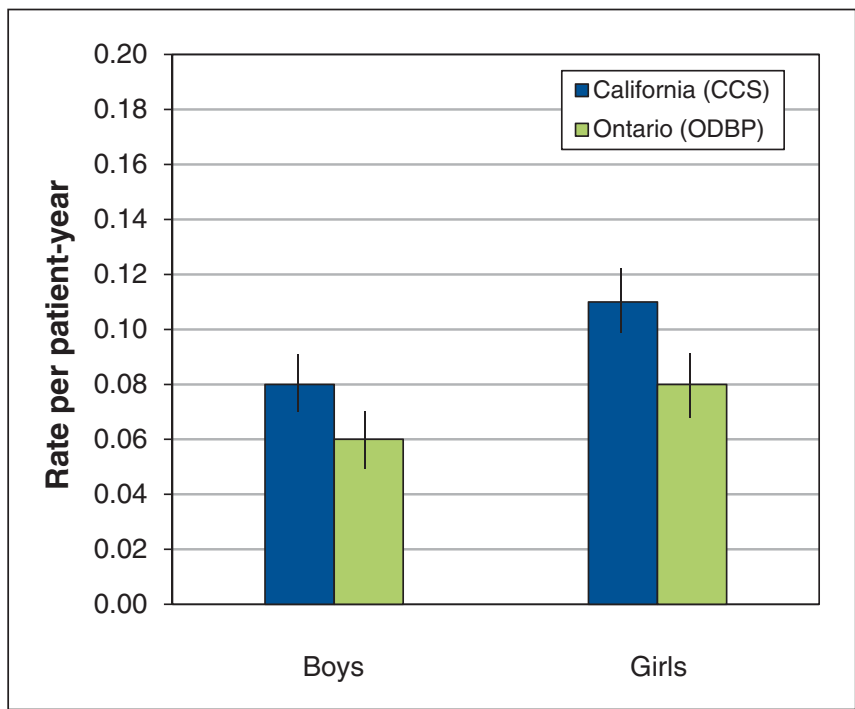

Figure 1: Age-standardized rates of hospital admission for diabetes mellitus complications, by sex, among children from low-income families in California and Ontario. Rates were higher for California children (absolute differences 0.02 [95\% confidence interval (Cl) $0.02-$ $0.02]$ /patient-year for boys; 0.03 [95\% Cl 0.03-0.03]/patient-year for girls). $\mathrm{CCS}=$ California Children's Services, ODBP = Ontario Drug Benefit Program.

Table 2: Comparison of other healthcare use by children with diabetes mellitus from low-income families in California and Ontario

\begin{tabular}{|c|c|c|c|}
\hline \multirow[b]{2}{*}{ Type of visit } & \multicolumn{3}{|c|}{ Jurisdiction } \\
\hline & $\begin{array}{l}\text { California } \\
n=4922\end{array}$ & $\begin{array}{c}\text { Ontario } \\
n=2050\end{array}$ & $p$ value* \\
\hline \multicolumn{4}{|l|}{ DM-routine visits } \\
\hline Proportion with $\geq 2$ visits per person-year, no. (\%) & $3185(64.7)$ & $1552(75.7)$ & $<0.001$ \\
\hline Visits per patient-year, mean $(95 \% \mathrm{Cl})$ & $2.85(2.80-2.90)$ & $3.40(3.35-3.45)$ & $<0.001$ \\
\hline \multicolumn{4}{|l|}{ Other hospital admissions } \\
\hline Admissions per patient-year, mean $(95 \% \mathrm{Cl})$ & $0.11(0.11-0.09)$ & $0.12(0.11-0.13)$ & 0.05 \\
\hline \multicolumn{4}{|c|}{ Rate of emergency department visits for DM complications $†$} \\
\hline Visits per patient-year, mean $(95 \% \mathrm{Cl})$ & $0.03(0.02-0.03)$ & $0.03(0.03-0.04)$ & 1.0 \\
\hline
\end{tabular}




\section{OPEN}

Research

low-income families in California. Pump use is higher among children from low-income families in California than in Ontario, and a substantial socioeconomic gradient exists within Ontario. Ontario has eligibility criteria for pump funding, but there are no such guidelines in California. Greater insulin pump use among children from low-income families in California may also be due to greater clinic support (care coordinators), comfort with pump use in high-risk populations, professional detailing

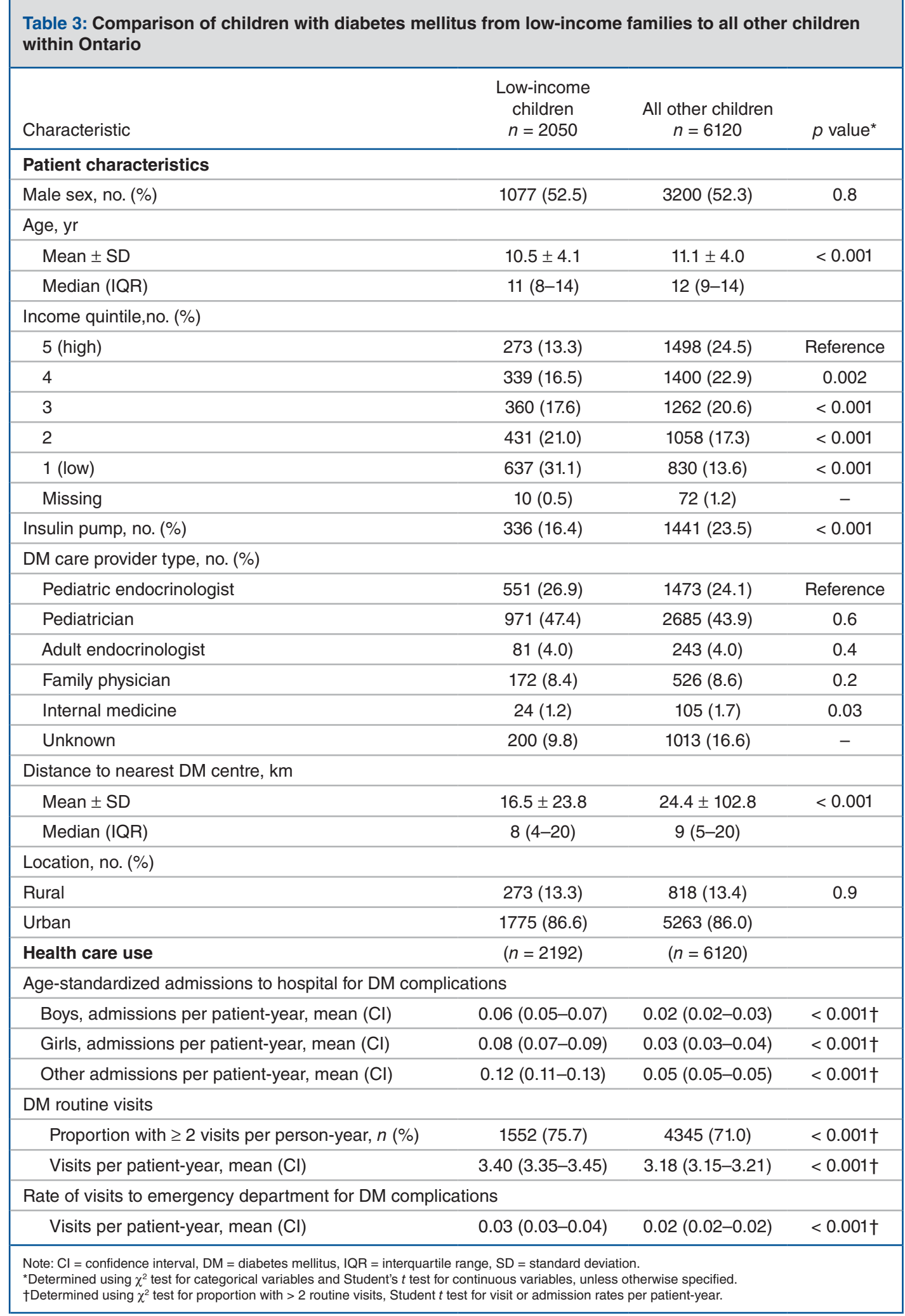


by pump manufacturers or commercial pressures resulting from a fee-for-service payment system. Ontario covers $100 \%$ of pump cost, but only $75 \%$ of pump supply costs, which may create a barrier for low-income families. Further research is needed to establish whether pumps can moderate socioeconomic gradients in health outcomes for children with diabetes and, if so, how best to support access to pumps for children from low-income families.

To gain insight into how best to structure health care systems to meet the needs of children with diabetes mellitus in low-income families, we focused our study to 2 settings in which we could clearly describe details of how the health systems are structured for readers to understand and contrast. California and Ontario were selected for our analysis to increase the generalizability of our study - they are the most populous state and province in the US and Canada, respectively, and share highly diverse populations with similar proportions of immigrants. ${ }^{18,34-36}$ However, some of the differences we saw in care and outcomes may be due to population differences.

\section{Limitations}

The administrative data from both jurisdictions were limited by lack of important information, such as direct measures of socioeconomic status and glycemic control. Low household income has been shown to be a strong determinant of health outcomes in children with diabetes mellitus, ${ }^{5-7}$ and our findings of higher rates of hospital admission for diabetes mellitus complications in Ontario children from low-income families compared with all other Ontario children are likely a reflection of the powerful effects of socioeconomic factors. Eligibility for California Children's Services required an annual household income of less than US\$22 050 in 2009 (or medical expenses > $20 \%$ of income), and most of the children in the Ontario Drug Benefit Program were in the lowest income quintiles (annual household income about Can\$20 000 for quintile 1 in 2009), ${ }^{37}$ suggesting comparability to children in California Children's Services. However, neighbourhood income quintile is a proxy measure of household income. Previous studies have shown good correlation between these data and individual household income in another Canadian province, and this method is widely used in Canadian health services research, ${ }^{38,39}$ but the precision of this ecologic method may be more limited in rural areas and by practices such as renting suites in homes.

For our comparisons involving children within Ontario with diabetes mellitus (those from low-income families versus all other children), we were unable to exclude children in the "all other" group who were taking oral hypoglycemic agents, because drug use data were only available for children in the Ontario Drug Benefit Program. A higher proportion of children with type 2 diabetes mellitus in the "all other" group may contribute to the lower rates of complications compared with children from low-income families (although rates of type 2 diabetes mellitus are very low in Canadian children ${ }^{16,40}$ ).

We used differing strategies for identifying children with diabetes mellitus in California Children's Services and Ontario. Our strategies have been used in prior analyses; ${ }^{12,13}$ however, the strategy used for California Children's Services has not been formally validated, and thus may contribute to differences between the study cohorts.

Finally, we were unable to contextualize our findings in California by comparing outcomes with children from higher income families, as there are no population-based California data for these children. To ensure the quality and validity of our analysis, we used comparable data sources from each country, created consistent definitions across jurisdictions, compared similar populations during the same time interval and carefully considered differences across systems that might explain the variation we observed. Nevertheless, this study highlights the challenges of such cross-jurisdictional analysis, because it is impossible to make causal assumptions of the health-system-level determinants of the outcomes measured.

\section{Conclusion}

Ontario children with diabetes mellitus from low-income families more commonly received routine diabetes care from generalists supported by a diabetes care network. These children were more likely to receive routine care and had rates of hospital admission for diabetes complications that were clinically comparable to those of children from low-income families in California. Developing diabetes networks that integrate generalists may play a role in increasing use of routine diabetes care and reducing complications for children. The significant disparities in outcomes within the universal access system in Ontario suggest an important research and policy focus to improve observed socioeconomic gradients in health outcomes for this growing population of children.

\section{References}

1. Dabelea D, Mayer-Davis EJ, Saydah S, et al.; SEARCH for Diabetes in Youth Study. Prevalence of type 1 and type 2 diabetes among children and adolescents from 2001 to 2009. FAMA 2014;311:1778-86.

2. Diabetes in Canada: highlights from the National Diabetes Surveillance System, 2004-2005. Public Health Agency of Canada; 2008. Available: www.phac-aspc. gc.ca/publicat/2008/dicndss-dacsnsd-04-05/index-eng.php (accessed 2015 May $15)$

3. O'Grady MJ, Delaney J, Jones TW, et al. Standardised mortality is increased three-fold in a population-based sample of children and adolescents with type 1 diabetes. Pediatr Diabetes 2013;14:13-7.

4. Edge JA, Ford-Adams ME, Dunger DB. Causes of death in children with insulin dependent diabetes 1990-96. Arch Dis Child 1999;81:318-23.

5. Hatherly K, Smith L, Overland J, et al. Glycemic control and type 1 diabetes: the differential impact of model of care and income. Pediatr Diabetes 2011; $12: 115-9$.

6. Shi L, Lu N. Individual sociodemographic characteristics associated with hospitalization for pediatric ambulatory care sensitive conditions. 7 Health Care Poor Underserved 2000;11:373-84.

7. Zuijdwijk CS, Cuerden M, Mahmud FH. Social determinants of health on glycemic control in pediatric type 1 diabetes. 7 Pediatr 2013;162:730-5.

8. California Children's Services: prooram overview. Sacramento (CA): California Department of Health Care Services; 2014. Available: www.dhcs.ca.gov/services/ ccs/Pages/ProgramOverview.aspx (accessed 2014 Apr. 1).

9. Swenson SM, Chamberlain LJ, Sanders LM, et al. Outpatient pharmacy expenditures for children with serious chronic illness in California, 20102012. 7AMA 2015;314:405-7.

10. CIHI data quality study of Ontario emergency department visits for 2004-2005: executive summary. Ottawa: Canadian Institute for Health Information; 2008.

11. CIHI data quality study of the 2009-2010 discharge abstract database. Ottawa: Canadian Institute for Health Information; 2012.

12. Lee JM, Sundaram V, Sanders L, et al. Health care utilization and costs of publicly-insured children with diabetes in California. 7 Pediatr 2015;167:44954.e6.

13. Guttmann A, Nakhla M, Henderson $M$, et al. Validation of a health administrative data algorithm for assessing the epidemiology of diabetes in Canadian children. Pediatr Diabetes 2010;11:122-8. 
14. Hux JE, Ivis F, Flintoft V, et al. Diabetes in Ontario: determination of prevalence and incidence using a validated administrative data algorithm. Diabetes Care 2002;25:512-6.

15. Juurlink D, Preyra C, Croxford R, et al. Canadian Institute for Health Information Discharge Abstract Database: a validation study. Toronto: Institute for Clinical Evaluative Sciences; 2006.

16. Shulman R, Miller FA, Stukel TA, et al. Resources and population served: a description of the Ontario Paediatric Diabetes Network. CMAf Open 2016;4:E141-6.

17. Single years of age and sex: 2010. Suitland (MD): United States Census Bureau; 2011. Available: http://factfinder2.census.gov/faces/tableservices/jsf/ pages/productview.xhtml? pid=DEC_10_SF1_QTP2 (accessed 2014 May 15).

18. Population centre. Ottawa: Statistics Canada; 2012 Available: http://www12. statcan.gc.ca/census-recensement/2011/ref/dict/geo049a-eng.cfm (accessed 2014 Apr. 20).

19. QuickFacts. California. Suitland (MD): United States Census Bureau; 2010. Available: www.census.gov/quickfacts/table/AGE275210/06 (accessed 2016 Sept. 20).

20. Annual population estimates by age group and sex at July 1, provincial perspective — Ontario [table]. Ottawa: Statistics Canada; 2010. Available: www.statcan.gc.ca/ pub/91-215-x/2012000/t518-eng.htm (accessed 2016 Sept. 20).

21. Pihoker C, Forsander G, Wolfsdorf J, et al. The delivery of ambulatory diabetes care to children and adolescents with diabetes. Pediatr Diabetes 2009;10(Suppl 12):58-70.

22. Chiang JL, Kirkman MS, Laffel LM, et al. Type 1 Diabetes Sourcebook Authors. Type 1 diabetes through the life span: a position statement of the American Diabetes Association. Diabetes Care 2014;37:2034-54.

23. Ontario Paediatric Diabetes Network current state survey report. Toronto: Provincial Council for Maternal and Child Health; 2013.

24. Mustard CA, Derksen S, Berthelot JM, et al. Assessing ecologic proxies for household income: a comparison of household and neighbourhood level income measures in the study of population health status. Health Place 1999;5:157-71.

25. US Department of Health and Human Services. The 2009 HHS Poverty Guidelines 2009. Federal Register 2009;74: 4199-201.

26. State Medicaid and CHIP income eligibility standards [table]. Baltimore: Center for Medicaid and CHIP Services; 2014. Available: www.medicaid.gov/ AffordableCareAct/Medicaid-Moving-Forward-2014/Downloads/Medicaid -and-CHIP-Eligibility-Levels-Table.pdf (accessed 2014 Apr. 1).

27. Hadden L, Zdeb M. ZIP code 411: a well-kept SAS® secret. Paper 143-31. Cary (NC): SAS Institute; 2014. Available: http://www2.sas.com/proceedings/ sugi31/143-31.pdf (accessed 2014 Apr. 20).

28. Rural-urban continuum codes. Washington (DC): United States Department of Agriculture Economic Research Service; 2013. Available: www.ers.usda.gov/ data-products/rural-urban-continuum-codes.aspx\#.U0 (accessed 2014 Apr. 20).

29. Diabetes short-term complications admission rate: technical specifications. Rockville (MD): Agency for Healthcare Research and Quality; 2013.

30. Amed S, Nuernberger K, McCrea P, et al. Adherence to clinical practice guidelines in the management of children, youth, and young adults with type 1 diabetes - a prospective population cohort study. 7 Pediatr 2013;163:543-8.

31. American Diabetes Association. Standards of medical care in diabetes 2014. Diabetes Care 2014;37(Suppl 1):S14-80.

32. Candian Diabetes Association. 2008 Clinical Practice Guidelines for the Prevention and Management of Diabetes in Canada. Can 7 Diabetes 2008;32(Suppl 1):S150-67.

33. Lee JM, Davis MM, Menon RK, et al. Geographic distribution of childhood diabetes and obesity relative to the supply of pediatric endocrinologists in the United States [published erratum in 7 Pediatr 2008;152:893]. 7 Pediatr 2008; 152:331-6

34. Ethnic diversity and immigration. Ottawa: Statistics Canada; 2012. Available: www.statcan.gc.ca/pub/11-402-x/2012000/chap/imm/imm-eng.htm?fpv=30000 (accessed 2015 May 15)

35. Population by year, by province and territory [table]. Ottawa: Statistics Canada; 2014. Available: www.statcan.gc.ca/tables-tableaux/sum-som/101/cst01/ demo02a-eng.htm (accessed 2015 May 15).
36. 15 states with the highest share of immigrants in their population. Washington (DC): Pew Research Center; 2014. Available: www.pewresearch.org/fact -tank/2014/05/14/15-states-with-the-highest-share-of-immigrants-in-their -population/ (accessed 2015 May 15).

37. Income Mobility: The Rich and Poor in Canada. Vancouver: The Fraser Institute; 2016. Available: https://www.fraserinstitute.org/sites/default/files/incomemobility-the-rich-and-poor-in-canada.pdf (accessed 2016 Nov. 22).

38. Kozyrskyj AL, Dahl ME, Chateau DG, et al. Evidence-based prescribing of antibiotics for children: role of socioeconomic status and physician characteristics. CMA7 2004;171:139-45.

39. Wang C, Guttmann A, To T, et al. Neighborhood income and health outcomes in infants: how do those with complex chronic conditions fare? Arch Pediatr Adolesc Med 2009;163:608-15.

40. Amed S, Dean HJ, Panagiotopoulos C, et al. Type 2 diabetes, medicationinduced diabetes, and monogenic diabetes in Canadian children: a prospective national surveillance study. Diabetes Care 2010;33:786-91.

Affiliations: Department of Paediatrics (Kaiser), University of California San Francisco, San Francisco, CA; Centre for Policy, Outcomes and Prevention (Sundaram, Sanders), Stanford University, Palo Alto, CA; Division of Paediatric Medicine, Department of Paediatrics (Cohen, Guttmann), Hospital for Sick Children and University of Toronto, Toronto, Ont.; Institute for Clinical Evaluative Sciences (Cohen, Shulman, Guan, Guttmann), Toronto, Ont.; Division of Endocrinology, Department of Paediatrics (Shulman), Hospital for Sick Children and the University of Toronto, Toronto, Ont.; Division of General Pediatrics (Sanders), Stanford University, Palo Alto, CA

Contributors: All of the authors were involved in the conceptualization and design of the study. Vandana Sundaram conducted the California Children's Services analysis. Jun Guan conducted the Ontario data analysis. Sunitha Kaiser interpreted both the Ontario and California analyses and drafted the manuscript. All of the authors critically revised the manuscript. All of the authors read and approved the final manuscript and agreed to act as guarantors of this work.

Disclaimer: No endorsement by the Centre for Policy, Outcomes and Prevention, Stanford University, should be inferred. This study was supported by the Institute for Clinical Evaluative Sciences (ICES), which is funded by an annual grant from the Ontario Ministry of Health and Long-Term Care (MOHLTC). The opinions, results and conclusions reported in this article are those of the authors and are independent from the funding sources. No endorsement by ICES or the Ontario MOHLTC is intented or should be inferred.

Funding: This work was supported in part with funding from the California Health Care Foundation. Astrid Guttmann receives salary support through an Applied Research Chair in Child Health Services Research from the Canadian Institutes of Health Research and operating funding for the Ontario analyses came from this Research Chair and with support from the Institute for Clinical Evaluative Sciences that is funded by an annual grant from the Ontario Ministry of Health and Long-Term Care. The Institute for Clinical Evaluative Sciences is a non-profit organization funded by the Ontario Ministry of Health and Long-Term Care with provision of population-based data. Parts of this paper are based on data compiled by the Canadian Institute for Health Information.

Supplemental information: For reviewer comments and the original submission of this manuscript, please see www.cmajopen.ca/content/4/4/ E729/suppl/DC1 